\title{
Product Group Actual Indicator
}

National Cancer Institute

\section{Source}

National Cancer Institute. Product Group Actual Indicator. NCI Thesaurus. Code C94022.

Specifies whether the product group is real (actual) vs. placeholder (kind of). 